\title{
Forest cover outside protected areas plays an important role in the conservation of the Vulnerable guiña Leopardus guigna
}

\author{
Nicolás Gálvez, Felipe Hernández, Jerry Laker, Horacio Gilabert \\ Robert Petitpas, Cristián Bonacic, Alessandro Gimona, Alison Hester \\ and DAVID W. MACDONALD
}

\begin{abstract}
Habitat loss and fragmentation are affecting populations of forest dwelling mammalian carnivores worldwide. In southern Chile, a biodiversity hotspot, anthropogenic activities have resulted in high loss of native forest cover. The guiña, or kodkod cat, Leopardus guigna is a small forest-dwelling felid with a narrow range in the temperate forest of southern Chile. The few existing studies of the species have suggested that it is almost exclusively restricted to large tracts of native forest. This paper reports a study in the temperate forest within a fragmented Andean piedmont landscape which demonstrates that smaller forest fragments in the farmland matrix are playing a key role in the persistence of the guiña. We estimated occupancy in both continuous native forest and remnant forest fragments and, with single-species/single-season models, evaluated the extent to which forest cover, habitat type and proximity to protected areas have a modulating effect on occupancy. A continuous survey during 2008-2009, in three seasons of 90-100 days each, accumulated 6,200 camera trap days and returned 47 photographs of guiña. Total detection in fragments was higher than in continuous forests, with detection confirmed in almost $70 \%$ of studied fragments. We found that probability of a site being occupied significantly increased with forest cover (adult/secondary forest, scrubland) and probability was low $(<0.2)$ in sites with $<50 \%$ of surrounding forest cover. Our study highlights the importance of remnant forest fragments in the mosaic of extensive agriculture for the spatial dynamics of a guiña population and hence for the future conservation of the species.
\end{abstract}

Nicolás GÁlveZ* (Corresponding author), Felipe HernándeZ, Jerry LaKer, Horacio Gilabert, Robert Petitpas and Cristián Bonacic Fauna Australis Wildlife Laboratory, School of Agriculture and Forestry Sciences, Pontifícia Universidad Católica de Chile, Chile. E-mail ngalvezr@uc.cl

Alessandro Gimona and Alison Hester The James Hutton Institute, Craigiebuckler, Aberdeen, UK

David W. Macdonald Wildlife Conservation Research Unit, Department of Zoology, University of Oxford, Tubney, UK

${ }^{*}$ Also at: Department of Natural Sciences, Centre for Local Development, Villarrica Campus, Pontificia Universidad Católica de Chile, Araucanía, Chile

Received 21 September 2011. Revision requested 16 November 2011.

Accepted 23 January 2012.
Keywords Cover, forest, fragment, guiña, Leopardus guigna, occupancy, protected area, southern Chile, temperate forest

\section{Introduction}

T abitat loss and fragmentation have been highlighted as 1 one of the most serious threats to biological diversity (Wilcove et al., 1998), particularly for species such as mammalian carnivores that range widely (Myers, 1994). The effects of habitat loss and fragmentation on forest dwelling carnivores are relatively unexplored and yet important for practical conservation (Sunquist \& Sunquist, 2001). One area suffering from extensive habitat loss and fragmentation is the Chilean temperate rainforest, a biodiversity hotspot (Conservation International, 2010). This region experienced rapid environmental change as a result of the expansion of forestry and agricultural activities throughout the 2oth century (Armesto et al., 1998; Willson et al., 2005). The guiña, or kodkod cat, Leopardus guigna is a small forest specialist endemic to this hotspot. Characteristics such as small size $(<2 \mathrm{~kg}$ ), low density (Dunstone et al., 2002) and preference for native forest (Acosta-Jamett \& Simonetti, 2004), make the guiña sensitive to landscape change (Sunquist \& Sunquist, 2001) and a potential indicator of the effects of fragmentation. Knowledge of the spatial ecology of the guiña could shed light on the consequences of habitat loss and fragmentation and thus inform conservation planning in these anthropogenic landscapes.

One of the world's smallest wild felids, the guiña is categorized as Vulnerable, with a decreasing population trend, on the IUCN Red List (Acosta \& Lucherini, 2008). The guiña is patchily distributed in a narrow range over latitudes $30-500^{\circ} \mathrm{S}$, corresponding to the forested Mediterranean and temperate rainforest biomes of Chile and Argentina (Redford \& Eisenberg, 1992; Nowell \& Jackson, 1996). Within the guiña's range large areas of native forest are limited to the coastal and Andean uplands, and the central valley is completely deforested. Large areas of native forest are often close to protected areas in the Andes and are surrounded by fragmented landscapes. However, most protected areas cover mountainous areas and uplands, and offer no protection to lower lying fragmented forests. 
Many threatened plant and animal communities appear to receive limited protection from the protected area system (Armesto et al., 1998; Pauchard \& Villarroel, 2002).

The few studies published on the guiña have suggested that the species is almost exclusively restricted to native Nothofagus forest (Acosta-Jamett \& Simonetti, 2004) and that it has been negatively affected by conversion of this forest to exotic pine plantations (Acosta-Jamett et al., 2003; Acosta-Jamett \& Simonetti, 2004). Protected areas with continuous forest are subject to extreme upland climates, whereas lowland unprotected areas are fragmented and are influenced to a greater extent by human activities, including direct impacts on the species such as killing in retribution for predation of poultry (Silva-Rodríguez et al., 2007). A coherent strategy for conservation of the guiña requires knowledge of its ecology and habitat use in the now typical anthropogenic matrix of forest fragments, fields and settlements.

Like many small felids the guiña is cryptic, rare, and lives in places where detection and monitoring is difficult (Macdonald et al., 2010). In such cases the use of occupancy has been proposed as a potential surrogate for the abundance of elusive species, particularly for strongly territorial species (MacKenzie et al., 2006). Estimation of site occupancy is useful for elusive species because it explicitly accounts for detection and false absences (MacKenzie et al., 2002, 2004, 2006). Occupancy modelling has thus become a useful tool for analysing habitat associations of carnivores living in forested habitats (e.g. O'Connell et al., 2006; Linkie et al., 2006, 2007) but has not been applied to the guiña.

Here we report the results of a study of the guiña using camera traps in an Andean piedmont landscape in the Araucanía district of Chile. This area has recently been designated a Biosphere Reserve (UNESCO, 2010). We estimated guiña occupancy for the first time in both continuous native forest and remnant, exploited forest patches surrounding highland protected areas, and evaluated the extent to which landscape level variables have a modulating effect on occupancy and detection. Our aim is to examine the importance of remnant forest fragments for the survival of the guiña.

\section{Study area}

This study was conducted near Pucón in the Lake Villarrica catchment of the Araucanía region, Chile. The comuna of Pucón lies at the northern limit of the South American temperate forest (Armesto et al., 1998). The natural vegetation of the area is deciduous southern beech forest, characterized by Nothofagus obliqua, Laurelia sempervirens, Eucryphia cordifolia, Podocarpus saligna and Aextoxicon punctatum in lowland forests. At higher altitudes the association graduates to Nothofagus dombeyi, Nothofagus alpina, Laureliopsis philippiana and Araucana araucana (Luebert \& Pliscoff, 2006). The elevation gradient of the catchment varies from $230 \mathrm{~m}$ in the agricultural valley to $>1,200 \mathrm{~m}$. The core protected areas of the Biosphere Reserve Araucarias are two National Parks, Huerquehue and Villarrica, and the Villarrica National Reserve (Fig. 1). These protected areas lie at altitudes $>800 \mathrm{~m}$.

\section{Methods}

We selected study sites in the Lake Villarrica catchment that represent continuous and fragmented native forest. The criteria for continuous forest were an area $>200$ ha and a southerly aspect. There are no large north-facing forests in this catchment, as these are still affected by wildfire damage sustained during colonization in the early 2oth century (Kitzberger \& Veblen, 1999). All chosen study sites are at elevations $<800 \mathrm{~m}$. Fragmented forests were defined as areas of $20-40$ ha separated by $>2 \mathrm{~km}$ from other fragments. ArcView v. 3.2 (ESRI, Redlands, USA) and ENVI v. 4.2 (ITT, Boulder, USA) were used to measure distances and the area of sites. Within our study area of $1,740 \mathrm{~km}^{2}$ there were six sites fitting the criteria for continuous forest and nine that qualified as fragments (Fig. 1).

Between January 2008 and March 2009 a total of 27 camera traps were deployed, operating continuously for a total of $>6,000$ camera-trap days. A distance of $2 \mathrm{~km}$ between traps, including forest fragments, was considered sufficient to ensure sampling independence because this distance is greater than the diameter of a guiña's home range (Dunstone et al., 2002). Two fragments were closer than $2 \mathrm{~km}$ but separated by a major watercourse, which was considered a natural barrier for guiña dispersal. A total of 18 camera traps were deployed in continuous forest and nine in forest fragments (Fig. 1). Three camera traps were placed systematically ( $>2 \mathrm{~km}$ apart) in each continuous forest, so that the whole forest site was surveyed. To ensure a funnelling effect in this forest, similar to a small fragment in the matrix, cameras were placed along forested ravines, which have been associated with high guiña activity (Sanderson et al., 2002). Ravines did not connect trap locations. Twelve of the camera traps in continuous forest were in areas adjacent to protected areas (i.e. connected through forest cover to higher elevations). One camera trap was placed in each small fragment. In total, 25 active (TM 1550) and 2 passive (TM 500) infrared cameras were deployed (Trailmaster, Inc., Lenexa, USA). Cameras were placed along trails, programmed to operate for $24 \mathrm{~h}$ per day, and visited for maintenance every $20-25$ days. To ensure that the active and passive cameras had similar detection zones we restricted placement of passive monitors (TM 500) to $<20 \mathrm{~cm}$ above ground (the same as for the active 


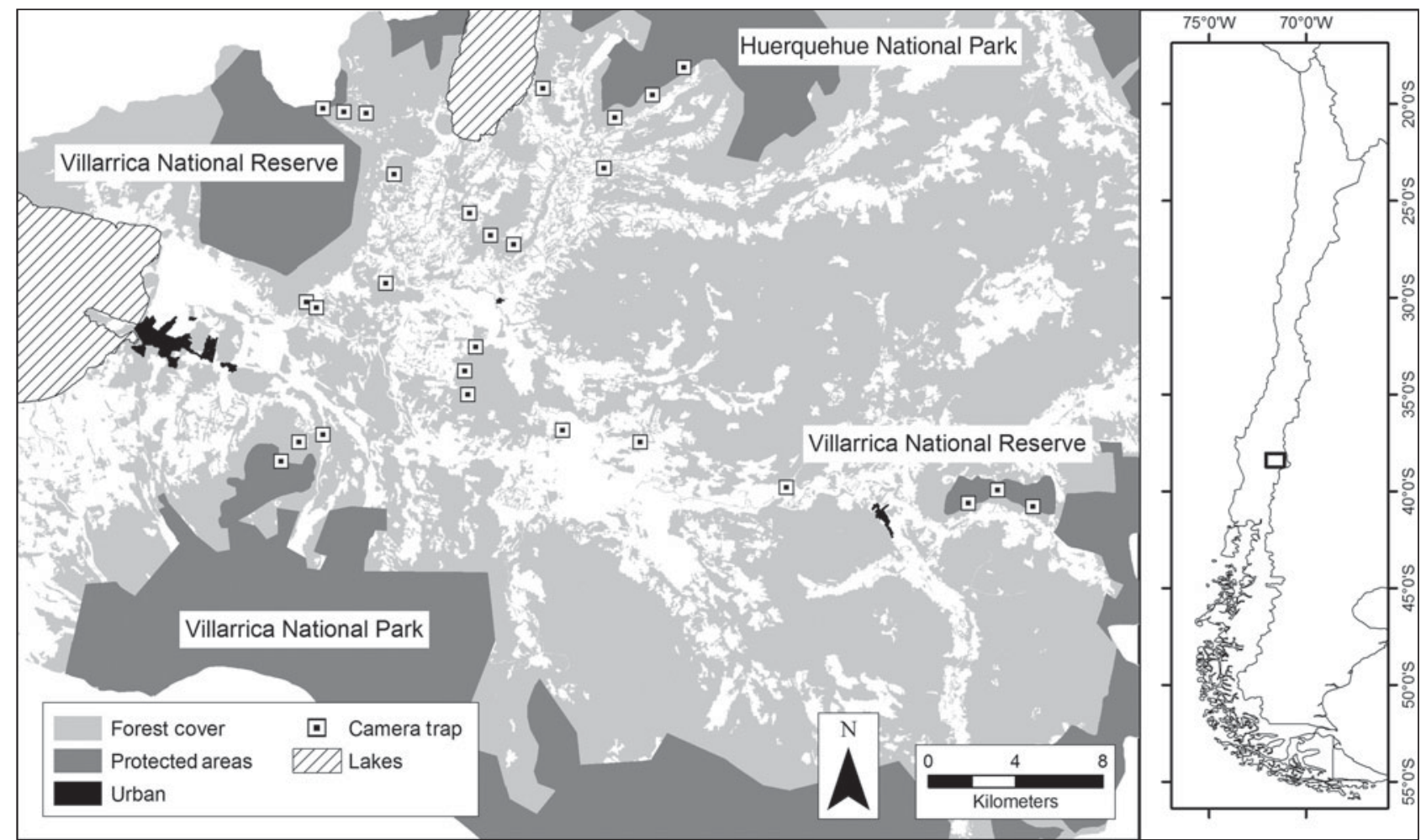

FIG. 1 Protected areas, forest cover and camera-trap sites in the Andean piedmont of the Araucanía district. The rectangle on the inset indicates the location of the main figure in southern Chile.

monitors), with a downward angle and a reduced detection width to prevent false triggers (Swann et al., 2004). In test trials Trailmaster active monitors (TM 1500) performed poorly on small species because they passed below the beam (Swann et al., 2004). However, the guiña is taller $(17-29 \mathrm{~cm})$ than the small model species (Martes sp., c. $8 \mathrm{~cm}$ ) used in the trial and both monitor types detected the guiña on repeated occasions. During the spring-summer season of 2008-2009 only 25 sites were included in the analysis because of camera malfunction (Table 1).

\section{Occupancy modelling}

The guiña has distinctive markings and therefore capturerecapture models may provide density estimates. However, it is our experience that the incidence of melanism (Plate $1 \mathrm{~b}$;

TABLE 1 Survey effort and seasonal variation in sites occupied by the guiña Leopardus guigna in continuous forests and fragments in the study area in the Araucanía district of southern Chile (Fig. 1).

\begin{tabular}{|c|c|c|c|}
\hline & $\begin{array}{l}\text { Summer-autumn } \\
2008\end{array}$ & $\begin{array}{l}\text { Winter } \\
2008\end{array}$ & $\begin{array}{l}\text { Spring-summer } \\
2008-2009\end{array}$ \\
\hline Number of camera-trap stations & 27 & 27 & 25 \\
\hline Survey effort (camera-trap days) & 2,360 & 1,630 & 2,210 \\
\hline Number of photographs & 18 & 16 & 13 \\
\hline Mean number of detections per station & 1.8 & 1.45 & 1.63 \\
\hline $\begin{array}{l}\text { Number of occupied stations } \\
\text { (proportion of total surveyed stations) }\end{array}$ & $10(0.37)$ & $11(0.41)$ & $8(0.32)$ \\
\hline \multicolumn{4}{|l|}{ Continuous forest ( 6 areas, 18 camera-trap stations) } \\
\hline $\begin{array}{l}\text { Number of occupied stations } \\
\text { (proportion of total surveyed stations) }\end{array}$ & $6(0.33)$ & $7(0.39)$ & $5(0.31)$ \\
\hline Proportion of stations occupied in previous season & & 0.71 & 0 \\
\hline Proportion of stations occupied in all seasons & & & 0.6 \\
\hline \multicolumn{4}{|l|}{ Fragmented forest ( 9 areas, 9 camera-trap stations) } \\
\hline $\begin{array}{l}\text { Number of occupied stations } \\
\text { (proportion of total surveyed stations) }\end{array}$ & $4(0.44)$ & $4(0.44)$ & $3(0.33)$ \\
\hline Proportion of stations occupied in previous season & & 0.5 & 0.33 \\
\hline Proportion of stations occupied in all seasons & & & 0 \\
\hline
\end{tabular}



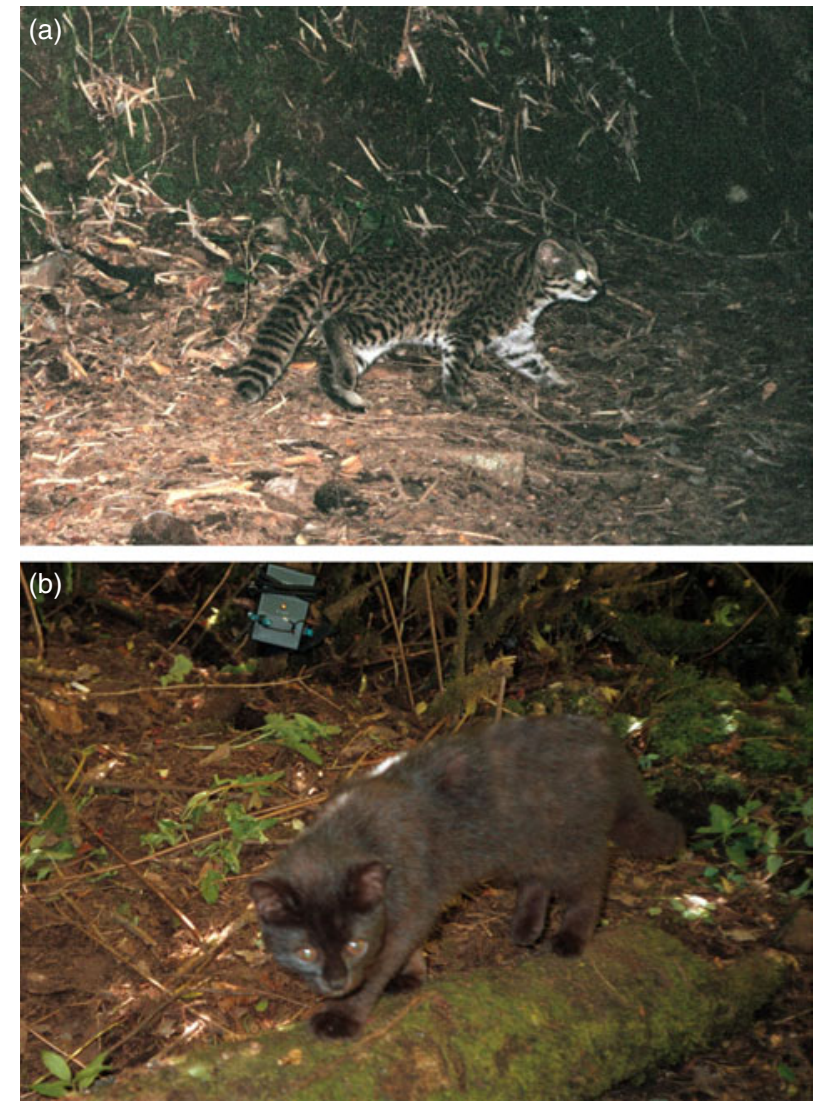

Plate 1 Spotted (a) and melanic (b) guiñas Leopardus guigna photographed by camera traps.

c. $30 \%$ of photos) and difficulties in obtaining photos of both sides of the animal support the use of occupancy models based on presence-absence data.

We compare competing hypotheses using a suite of candidate models of occupancy $(\psi)$ and detection $(p)$ parameters, following MacKenzie et al. (2006). For $\psi$, we tested landscape covariates that represent three conditions for the sites: (1) amount of forest cover surrounding a site, (2) habitat type (i.e. continuous vs fragmented), and (3) whether a site is in a forest adjacent to a protected area. The amount of forest cover was determined by cover of mature forest, secondary forest, and scrubland, expressed as the proportion within a circular buffer of $1 \mathrm{~km}$ radius around each camera. To test which landscape variables explained detection probability $(p)$, as a proxy for activity, we assessed: (1) road density as the total length (m) within the buffer area $\left(\mathrm{km}^{2}\right),(2)$ distance to the nearest inhabited human household, and (3) distance to the nearest major river that could be acting as a potential corridor. The simplest model, with constant $\psi$ and $p$ (i.e. $\psi(),. p()$.$) was compared with models$ that incorporated landscape covariates. All combinations were assessed with one covariate per $\psi$ and $p$ model (e.g. $\psi($ forestcover $), p$ (river)). More covariates per model were not considered because of model over-parameterization, which would reduce the precision of occupancy estimates
(Donovan \& Hines, 2007). Camera positions and altitudes were recorded using a global positioning system. The position of rivers and human settlements were obtained from 1:10,000 digital cartography. Land use was derived from $1: 10,000$ geographical information system vector coverage (LPT-UCT, 2009).

Binary detection histories were constructed for each camera trap and collapsed into 10-day blocks (sampling occasions). Thus, for each site and each occasion, 1 indicated the detection of guiña, and o indicated non-detection. We compared different sample aggregations (i.e. 5, 10 and 20 days) and found that 10 days generated reliable estimates of detection probability (by reducing the $0: 1$ ratio) whilst minimizing loss of detections of guiña. Malfunctions between maintenance checks were treated as missing observations. We assumed closure to occupancy changes by restricting the sampling period to 90-100 days (9-10 sampling occasions; e.g. Linkie et al., 2006). The survey was divided into three periods: summer-autumn 2008, winter 2008, and spring-summer 2008-2009.

We estimated $\psi$ and $p$ for each period using maximum likelihood (MacKenzie et al., 2006), with single-species/ single-season models, with PRESENCE (Hines, 2006). Akaike information criterion (AIC) values were used to identify the model best supported by the observed data. AIC values and model weights were corrected for small sample size (AICc; Burnham \& Anderson, 1998). We only considered models with $\triangle \mathrm{AICc}<2$ for the analysis because they have substantially more support (Burnham \& Anderson, 1998). Akaike weights were calculated for all models, providing an indication of evidence in favour of a given model within the set (Burnham \& Anderson, 1998). Evidence in favour of a particular variable was obtained from the evidence ratio as the sum of model weights, where the variable was included, divided by the reciprocal of the sum (MacKenzie et al., 2006).

The effect of site-specific covariates on $\psi$ or $p$ was explored by means of a logit-link function (i.e. logistic regression), assessed with the $95 \%$ confidence interval (CI) of the $\beta_{1}$ regression parameter (MacKenzie et al., 2006). We used a one-sided CI for the $\psi$ forest cover covariate following MacKenzie et al. (2006) as we expected a positive association with forest cover (Dunstone et al., 2002; AcostaJamett \& Simonetti, 2004). Significance of the covariate effect on the parameter was accepted if o was not included in the $\beta_{1}$ confidence interval (MacKenzie et al., 2006). Beta parameters, $\beta_{0}$ and $\beta_{1}$, were estimated with PRESENCE (Hines, 2006).

We used the weights of models with a $\Delta$ AICc $<2$ to obtain model averaged estimates of $\psi$ and $p$ following Burnham \& Anderson (1998). Precision of models for the estimated $\psi$ parameter were obtained following Linkie et al. (2006) as SE(estimate) $/ \psi$ estimate $\times 100$. Models with convergence problems because of parameters near allowable 
values (i.e. o and 1) were eliminated (e.g. MacKenzie et al., 2004). To contribute to further studies of the species we determined the amount of survey effort needed to increase parameter precision considering two a priori SE values (0.05 and 0.1). We followed the standard design described in MacKenzie \& Royle (2005) and used average estimates of $\psi$ and $p$.

\section{Results}

During 2008-2009 6,200 camera-trap days returned 47 photographs of the guiña (Plate 1 ). Over the entire survey period guiñas were detected in $50 \%$ of the 18 continuous forest sites and $67 \%$ of the nine fragmented forest sites. The naïve estimate of $\psi$ of occupied sites (i.e. not accounting for detection probability) was similar across seasons (mean $0.37 \pm$ SD 0.04; Table 1); $15 \%$ of the 27 sites were occupied during only one season, $19 \%$ during two consecutive seasons, $11 \%$ during two non-consecutive seasons (i.e. summer-autumn and spring-summer) and $11 \%$ during all three seasons. Only sites in continuous forest were occupied during all three seasons, corresponding to $17 \%$ of the 18 total sites and $60 \%$ of sites $(n=5)$ occupied during the final season (Table 1). Continuous forests had relatively higher number of occupied sites (i.e. naïve estimate) during consecutive seasons compared to fragments (Table 1).

Occupancy models, explicitly accounting for variability in detection, suggest that the proportion of sites occupied by guiñas was higher during summer-autumn than springsummer (Table 2). Models for winter were not analysed because of unreliable estimates caused by a small number of detections per site (e.g. only one detection during the season) and a high number of sites where the species was detected (Table 1). Models had relatively good precision (mean 28.7 \pm SD 5.6), compared to other elusive species (Linkie et al., 2007).

The amount of forest cover consistently showed more support than any other variable in explaining occupancy. None of the categorical variables (continuous vs fragmented forest, or if a site was adjacent to a protected area) showed any support (Table 2 ). In summer-autumn the evidence ratio for forest cover had $4.0 \times$ the support of the constant model (Table 2) and appeared to have an effect on $\psi$ but the magnitude was poorly supported $\left(\beta_{1}=0.102,95 \%\right.$ $\mathrm{CI}=-0.0622, \infty)$. During spring-summer evidence in favour of forest cover was $4.8 \times$ that of the constant model (Table 2) and probability of a site being occupied significantly increased with forest cover (highest ranked model $\left.\beta_{0}=-4,401, \quad \beta_{1}=0.062,95 \% \quad \mathrm{CI}=0.0183, \infty\right)$. Therefore we plotted $\psi$ for forest cover values (i.e. $0-100$ ) using the logit-link function: $\psi=\exp \left(\beta_{0}+\beta_{1} *\right.$ covariate $) /$ $\left(1+\exp \left(\beta_{0}+\beta_{1} *\right.\right.$ covariate $)$. The plot we observed showed that sites with $>80 \%$ and $<50 \%$ surrounding forest cover had a high $(>0.6)$ and low $(<0.2)$ probability of being occupied, respectively.

Detection probability of the guiña was low (Table 2). During summer-autumn the evidence ratio for distance to inhabited human households had $4.0 \times$ greater support than the constant model (Table 2), and detection significantly increased near human households $\left(\beta_{0}=-2.41\right.$, $\left.\beta_{1}=-0.190,95 \% \mathrm{CI}=-0.377,-0.003\right)$. During springsummer all covariates for detections had similar support (Table 2) but relationships were not significant.

We determined that to obtain a parameter precision of SE of 0.05 and 0.1 , based on the spring-summer model

TABLE 2 Estimated proportion of sites occupied $(\hat{\psi})$ and detection probability $(p)$ of best fitting models for the guiña during summerautumn 2008 and spring-summer 2008-2009.

\begin{tabular}{|c|c|c|c|c|c|c|}
\hline Model $^{1}$ & $\Delta \mathrm{AIC}_{\mathrm{c}}{ }^{2}$ & $w i^{3}$ & $\mathrm{~K}^{4}$ & Est. $\hat{\psi}(\mathrm{SE})^{5}$ & Est. $p(\mathrm{SE})^{6}$ & Model precision \\
\hline \multicolumn{7}{|l|}{ Summer-autumn $2008^{7}$} \\
\hline$\hat{\psi}($ forestcover $), p$ (human) & 0 & 0.80 & 4 & $0.69(0.13)$ & $0.09(0.03)$ & 18.84 \\
\hline$\hat{\psi}(),. p()$. & 2.76 & 0.20 & 2 & $0.70(0.28)$ & $0.08(0.04)$ & 40.00 \\
\hline \multicolumn{7}{|l|}{ Spring-summer 2008-2009 } \\
\hline$\hat{\psi}($ forestcover $), p()$. & 0 & 0.26 & 3 & $0.43(0.14)$ & $0.14(0.05)$ & 32.56 \\
\hline$\hat{\psi}($ forestcover $), p$ (human) & 0.03 & 0.26 & 4 & $0.53(0.12)$ & $0.13(0.04)$ & 22.64 \\
\hline$\hat{\psi}$ (forestcover), $p$ (river) & 0.59 & 0.20 & 4 & $0.53(0.16)$ & $0.11(0.04)$ & 30.19 \\
\hline$\hat{\psi}(),. p()$. & 0.91 & 0.17 & 2 & $0.45(0.16)$ & $0.13(0.05)$ & 35.56 \\
\hline$\hat{\psi}($ forestcover $), p($ road $)$ & 1.65 & 0.12 & 4 & $0.45(0.13)$ & $0.17(0.06)$ & 28.89 \\
\hline Model average & & & & $0.48(0.14)$ & $0.13(0.05)$ & \\
\hline
\end{tabular}

${ }^{1}$ Covariates of top ranked models are amount of forest cover (forestcover) and road density (road) in $\mathrm{m} \mathrm{km}{ }^{-2}$ within a $1 \mathrm{~km}$ radius buffer around camera-trap stations; human, distance to households; river, distance to nearest major river

${ }^{2}$ Difference of Akaike information criteria corrected for small sample size from the top ranked model

${ }^{3} \mathrm{AIC}_{\mathrm{c}}$ model weight

${ }^{4}$ Number of parameters

${ }^{5}$ Estimated proportion of sites occupied

${ }^{6}$ Estimated detection probability

${ }^{7}$ Model average was not calculated because only one model had substantial support (i.e. $\Delta$ AIC $_{c}<2$ ) 
average with 10 surveys, a total of 225 and 56 sites would need to be sampled, respectively.

\section{Discussion}

Estimates of site occupancy suggest that forest fragments in agricultural landscapes are as important for the guiña as continuous forests adjacent to protected areas. Our findings differ from those of Acosta-Jamett \& Simonetti (2004), who highlighted the importance of continuous native forest for the guiña compared to a peripheral matrix of native forest fragments and exotic pine plantations. Our results suggest that native forest fragments of $20-40$ ha continue to be habitat for the guiña in agricultural landscapes, and potentially provide connectivity between protected areas and/or private continuous forests.

The guiña is able to use these remnant patches, and the patches may be playing an important role in maintaining long-term population viability (Acosta-Jamett et al., 2003). However, our results suggest that the amount of surrounding native forest cover has a modulating effect on occupancy, indicating that the landscape-level context of each fragment is also important. Native vegetation (i.e. mature and secondary forest and scrubland) may facilitate the movement of guiñas (Dunstone et al., 2002), serving as corridors, and smaller patches as stepping-stones that connect fragments or larger forested areas (Sanderson et al., 2002). Forest cover could also increase the amount of available resources associated with these particular fragments, providing a high-value mosaic of habitats that combine both refuge and food resources within the guiña's home range.

Higher turnover of site occupation (i.e. naïve estimate) in fragments relative to continuous forests (Table 1) could reflect seasonal movements of individuals in the matrix, further suggesting fragments act as connections between areas of continuous forest. However, some fragmented sites were occupied repeatedly (Table 1), suggesting possible use of the agricultural matrix as permanent territory; this has been confirmed with preliminary telemetry results (E. Schüttler, pers. comm.). Despite this, continuous forests may be the more significant habitat for the guiña in a metapopulation context (Acosta-Jamett et al., 2003), and thus a network of forest habitat within the agricultural matrix connecting with surrounding intact forests may be important.

Conservation in anthropogenic landscapes is also related to the threat of direct persecution of the species by rural communities, prompted by perceived conflict. Retributive killing is one of the main threats to the guiña (SilvaRodríguez et al., 2007). Anecdotal reports from our study area, based on interviews with farmers, suggest there has been a reduction in sightings of guiñas in the last 20 years and that attacks on poultry are infrequent. However, when attacks occur and a guiña is found inside a chicken coup, retributive killing by rural farmers is probably the general response, facilitated by the species' typical tree-climbing escape behaviour, which makes it easy to kill (Gálvez \& Bonacic, 2008).

The perception of farmers that sightings of and attacks by guiñas are now less frequent is at odds with our detection of the species near households. Notwithstanding that the perceptions of farmers in this context is unreliable, perceptions of a decline in sightings could relate to a detection effect because of long-term land-use change. Forest cover in the agricultural landscape of the study area has increased since the 1970s (Petitpas, 2010) and therefore it is possible that the natural prey of guiñas is now more available in some areas and they consequently need to prey less on poultry (Cavalcanti et al., 2010). The relative importance to guiña population dynamics of direct killing vs habitat loss, with the effects of reduction of prey on the long-term survival of the species warrants further work, as has been done for other species (e.g. Chapron et al., 2008).

An important question remains: is there a threshold at which fragmentation and habitat loss limit use, and dispersal of individuals, in the anthropogenic landscape and thus jeopardize persistence? From our study we conclude there is a level of habitat loss (i.e. $<50 \%$ forest cover) below which the probability of occupancy of a particular fragment becomes exceedingly low $(<0.2)$, so there could be a threshold of habitat loss and connectivity that limits colonization potential and thus long-term survival (Hanski, 1998). Understanding this threshold could improve predictive distribution models of the species and conservation management in fragmented landscapes (Hanski, 1998) in the contexts of increasing human pressure for development, and the effects of climate change on Chilean native forests. Human populations and deforestation are increasing in this temperate rainforest (Willson et al., 2005) and climate change may be an emerging threat (Malcolm et al., 2005). Future research should explore biologically relevant fragmentation metrics to elucidate further the effects of habitat loss and fragmentation, and the seasonal dynamics of the guiña. This research should focus on providing information for planning protected networks of suitable habitat and ensuring the long-term conservation of the guiña in anthropogenic landscapes.

Given the elusive nature of this felid there are some methodological considerations for this research. Low detection probabilities present particular difficulties for the monitoring of cryptic and elusive species such as the guiña. Although camera-trap surveys of large- and mediumsized carnivores have achieved detection probabilities $>0.3$ (O'Connell et al., 2006; Linkie et al., 2006, 2007), our estimates were $<0.15$, which puts limits on the reliability of occupancy estimates (MacKenzie et al., 2002). It is therefore 
imperative to assess multiple detection methods that could improve the detection of the species (e.g. O'Connell et al., 2006). Previous guiña presence-absence studies did not explicitly estimate and correct for detection probability (Acosta-Jamett \& Simonetti, 2004), possibly affecting inferences about habitat relationships in fragmented habitats.

In any case, a substantial increase in survey effort is needed to obtain more precise parameters and for further monitoring. For species with a low detection probability it may be better to survey more sites (e.g. camera-trap placements) less intensively (i.e. over fewer occasions) to produce more precise occupancy estimates (MacKenzie \& Royle, 2005). The estimated range of sites (i.e. 56-225 sites) required to improve precision of parameters should be sampled over short intervals during one season. An improvement in detection and an increase in effort could permit assessment of the rate of change in site occupancies over time (e.g. colonization and extinction probabilities) and thus a better understanding of dynamics in fragmented landscapes.

Finally, our study shows that a carnivore considered a forest specialist has some tolerance to habitat loss and fragmentation in an anthropogenic landscape surrounding protected areas. However, there is evidence suggesting a threshold value of forest cover, which, if better understood, could help inform future conservation actions for the species. Although this requires further assessment it points to the need to complement the protected area system with conservation measures targeted at farmers and landowners. Environmental education and on-farm protection of forest cover should aim to improve the quality and area of habitat refugia, and decrease the tendency to kill guiñas caught predating poultry.

The findings from this study have been presented to the biodiversity committee for the Araucanía region (led by the Ministry of Environment) and have informed an evaluation of proposed protected area extensions within the Biosphere Reserve. This research is ongoing, with a focus on understanding seasonal occupancy dynamics of the guiña in human-dominated landscapes, and assessing the relative impacts of habitat fragmentation and human persecution on the presence of the species.

\section{Acknowledgements}

We would like to thank M. Miranda, O. Ohrens, C, Rios, T. Murphy, F. Vidal, R.A. Griffiths, D. Sewell, J.J. LahozMonfort and G. Guillera-Arroita for valuable support and advice. We are grateful to two anonymous reviewers for their valuable critiques, and to the forestry and wildlife services of Chile (CONAF-SAG) for permits and support at various stages of this work. Field work was supported by a Darwin Initiative project (15/06) and Ministry of
Environment-Chile (FPA 2009-2010). We are very grateful to the many landowners who kindly permitted work on their land. F. Hernández and N. Gálvez were supported by CONICYT-Chile.

\section{References}

Acosta, G. \& Lucherini, M. (2008) Leopardus guigna. In The IUCN Red List of Threatened Species v. 2011.1. Http://www.iucnredlist.org [accessed 20 September 2011].

Acosta-Jamett, G. \& Simonetti, J.A. (2004) Habitat use by Oncifelis guigna and Pseudalopex culpaeus in a fragmented forest landscape in central Chile. Biodiversity Conservation, 13, 1135-1151.

Acosta-Jamett, G., Simonetti, J.A., Bustamante, R.O. \& Dunstone, N. (2003) Metapopulation approach to assess survival of Oncifelis guigna in fragmented forests of central Chile: a theoretical model. Mastozoología Neotropical (Arg.), 10, 217-229.

Armesto, J.J., Rozzi, R., Smith-Ramírez, C. \& Arroyo, M.T.K. (1998) Conservation targets in South American temperate forests. Science, 282, 1271-1272.

Burnham, K.P. \& Anderson, D.R. (1998) Model Selection and Inference: A Practical Information-Theoretic Approach. Springer, New York, USA.

Cavalcanti, S.M.C., Marchini, S., Zimmermann, A., Gese, E.M. \& Macdonald, D.W. (2010) Jaguars, livestock, and people in Brazil: realities and perceptions behind the conflict. In Biology and Conservation of Wild Felids (eds D.W. Macdonald \& A.J. Loveridge), pp. 383-402. Oxford University Press, Oxford, UK.

Chapron, G., Miquelle, D.G., Lambert, A., Goodrich, J.M., Legendre, S. \& Clobert, J. (2008) The impact on tigers of poaching versus prey depletion. Journal of Applied Ecology, 45, $1667-1674$.

Conservation International (2010) Biodiversity Hotspots. Centre for Applied Biodiversity Science. Http://www.biodiversityhotspots. org [accessed 20 September 2011].

Donovan, T.M. \& Hines, J. (2007) Exercises in Occupancy Modelling and Estimation. Http://www.uvm.edu/envnr/vtcfwru/spreadsheets/ occupancy/occupancy.htm [accessed 20 September 2011].

Dunstone, N., Durbin, L., Wyllie, I., Freer, R., Acosta, G., Mazzolli, M. \& Rose, S. (2002) Spatial organization, ranging behaviour and habitat use of the kodkod (Oncifelis guigna) in southern Chile. Journal of Zoology, 257, 1-11.

GÁlveZ, N. \& BonacıC, C. (2008) Filling gaps for guiña cat (kodkod) conservation in southern Chile. Wild Felid Monitor: Newsletter of Wild Felid Research and Management Association (WFA), 1, 13.

HansKi, I. (1998) Metapopulation dynamics. Nature, 396, 41-49.

Hines, J.E. (2006) PRESENCE v. 3.0-Software to Estimate Patch Occupancy and Related Parameters. Http://www.pwrc.usgs.gov [accessed 20 January 2010].

Kitzberger, T. \& Veblen, T.T. (1999) Fire-induced changes in northern Patagonian landscapes. Landscape Ecology, 14, 1-15.

Linkie, M., Chapron, G., Martyr, D.J., Holden, J. \& Leader-Williams, N. (2006) Assessing the viability of tiger subpopulations in a fragmented landscape. Journal of Applied Ecology, 43, 576-586.

Linkie, M., Dinata, Y., Nugroho, A. \& Haidir, I.A. (2007) Estimating occupancy of a data deficient mammalian species living in tropical rainforests: sun bears in the Kerinci Seblat region, Sumatra. Biological Conservation, 137, 20-27.

LPT-UCT (2009) Geographic Information System for the Villarrica Catchment. Information provided by the Land-use Laboratory (LPT) of the Catholic University of Temuco (UCT), Chile. 
Luebert, F. \& Pliscoff, P. (2006) Sinopsis bioclimática y vegetacional de Chile. Editorial Universitaria, Santiago, Chile.

Macdonald, D.W., Loveridge, A.J. \& Nowell, K. (2010) Dramatis personae: an introduction to the wild felids. In Biology and Conservation of Wild Felids (eds D.W. Macdonald \& A.J. Loveridge), pp. 3-58. Oxford University Press, Oxford, UK.

MacKenzie, D.I., Nichols, J.D., Lachman, G.B., Droege, S., Royle, J.A. \& LAngtimm, C.A. (2002) Estimating site occupancy rates when detection probabilities are less than one. Ecology, 83, 2248-2255.

MacKenzie, D.I. \& Royle, J.A. (2005) Designing efficient occupancy studies: general advice and tips on allocation of survey effort. Journal of Applied Ecology, 42, 1105-1114.

MacKenzie, D.I., Royle, J.A., Brown, J.A. \& Nichols, J.D. (2004) Occupancy estimation and modeling for rare and elusive populations. In Sampling Rare or Elusive Species (ed. W.L. Thompson), pp. 149-172. Island Press, Washington, DC, USA.

MacKenzie, D.I., Royle, J.A., Nichols, J.D., Pollock, K.H., Bailey, L.L. \& Hines, J.E. (2006) Occupancy Estimation and Modeling: Inferring Patterns and Dynamics of Species Occurrence. Academic New York, New York, USA.

Malcolm, J.R., Liu, C., Neilson, R.P., Hansen, L. \& Hannah, L. (2005) Global warming and extinctions of endemic species from biodiversity hotspots. Conservation Biology, 20, 538-548.

Myers, N. (1994) Global biodiversity II: losses. In Principles of Conservation Biology (eds G.K. Meffe \& C.R. Carroll), pp. 110-140. Sinauer Associates, Sunderland, USA.

Nowell, K. \& Jackson, P. (1996) Wild Cats: Status Survey and Conservation Action Plan. IUCN, Gland, Switzerland.

O'Connell, A.F., Talancy, N.W., Bailey, L.L., Sauer, J.R., Cook, R. \& Gilbert, A.T. (2006) Estimating site occupancy and detection probability parameters for meso- and large mammals in a coastal ecosystem. Journal of Wildlife Management, 70, 1625-1633.

Pauchard, A. \& Villarroel, P. (2002) Protected areas in Chile: history, current status and challenges. Natural Areas Journal, 22, 318-330.

Petitpas, R. (2010) Cambios en los patrones espaciales del paisaje: caso de estudio en un valle pre-cordillerano en la Región de la Araucanía, Chile. Undergraduate thesis, Faculty of Agriculture and Forestry, Pontificia Universidad Católica de Chile, Santiago, Chile.

Redford, K.H. \& EisenberG, J.F. (1992) Mammals of the Neotropics: Chile, Argentina, Uruguay, Paraguay. University of Chicago Press, Chicago, USA.
Sanderson, J., Sunquist, M.E. \& Iriarte, J.A. (2002) Natural history and landscape-use of guignas (Oncifelis guigna) on Isla Grande de Chiloé, Chile. Journal of Mammalogy, 83, 608-613.

Silva-Rodríguez, E.A., Ortega-Solís, G.R. \& Jiménez, J.E. (2007) Human attitudes toward wild felids in a human-dominated landscape of southern Chile. Cat News, 46, 17-19.

Sunquist, M.E. \& Sunquist, F. (2001) Changing landscapes: consequences for carnivores. In Carnivore Conservation (eds J.L. Gittleman, S.M. Funk, D.W. Macdonald \& R. Wayne), pp. 399-418. Cambridge University Press, Cambridge, UK.

Swann, D.E., Hass, C.C., Dalton, D.C. \& Wolf, S.A. (2004) Infrared-triggered cameras for detecting wildlife: an evaluation and review. Wildlife Society Bulletin, 32, 357-365.

UNESCO (2010) The World Network of Biosphere Reserves: 13 New Biosphere Reserves. United Nations Educational, Scientific and Cultural Organization, Paris, France. Http://www.unesco.org/new/ en/unesco [accessed 1 September 2010].

Wilcove, D.S., Rothistein, D., Dubow, J., Phillips, A. \& Losos, E. (1998) Quantifying threats to imperiled species in the United States. BioScience, 48, 607-615.

Willson, K., Newton, A., Echeverría, C., Weston, C. \& BURGMAN, M. (2005) A vulnerability analysis of the temperate forests of south central Chile. Biological Conservation, 122, 9-21.

\section{Biographical sketches}

N. GÁlvez is interested in carnivores, guild dynamics, and educational resources for wildlife conservation. F. HERNÁNDEZ is a veterinarian interested in temperate forest wildlife and disease transmission from invasive species. J. LAKER's interests include ungulate population ecology and farmer-wildlife interactions. H. Gilabert is interested in mathematical models applied to natural resource management and conservation. $R$. PETITPAS is interested in landscape ecology, in particularly the interactions between society and the environment. C. BONACIC is a veterinarian and wildlife manager, and Director of Fauna Australis. A. Gimona is a spatial ecologist and geographer interested in mechanistic and statistical models of species' distributions in terrestrial and aquatic systems. A. HESTER's research interests include plant-herbivore interactions and vegetation dynamics, biodiversity, conservation and range management. D.W. Macdonald is the founding Director of the Wildlife Conservation Research Unit at Oxford University, UK, and has studied 21 of the 37 species of felid. 